\title{
EVALUASI KINERJA DAN TEBAL LAPIS PERKERASAN DENGAN MENGGUNAKAN METODE BINA MARGA 2013 DAN DRAINASE JALAN
}

\author{
(Studi Kasus Jalan Raya Benculuk Kec. Cluring Kab. Banyuwangi)
}

\author{
Akhmad Widya Priawitama ${ }^{1}$, Rofi Budi Hamduwibawa ${ }^{2}$, Taufan Abadi ${ }^{3}$. \\ Program Studi Teknik Sipil, Fakultas Teknik, Universitas Muhammadiyah Jember ${ }^{1}$ \\ Jalan Karimata 49, Jember 68121, Indonesia \\ Program Studi Teknik Sipil, Fakultas Teknik, Universitas Muhammadiyah Jember ${ }^{2}$ \\ Jalan Karimata 49, Jember 68121, Indonesia \\ Program Studi Teknik Sipil, Fakultas Teknik, Universitas Muhammadiyah Jember ${ }^{3}$ \\ Jalan Karimata 49, Jember 68121, Indonesia
}

\begin{abstract}
Road is an infrastructure which supports and plays an important role in the transportation sector. The improvement of land transportation infrastructure can support the smooth and equitable development in regional and national levels.. Benculuk highway well known as highway of various destinations. With these conditions, it is necessary to evaluate the thickness of the flexible pavement on the road. Therefore a good handling construction of normalization, enhancement or rehalibitation is needed. It will be done optimally if the factors causing the damage are known. The problem in this research is how the performance of the Benculuk highway, how to evaluate the condition of the thickness of the flexible pavement using the 2013 UR 20-year Bina Marga method, and how to evaluate the dimensions of the road drainage channel. This study aims to (1) analyze performance on the Benculuk highway, (2) analyze the flexible pavement conditions with the 2013 UR 20-year Bina Marga method (3) evaluate the dimensions of the road drainage channel. The results of the 2013 Bina Marga pavement thickness calculation obtained a flexible pavement thickness $47.5 \mathrm{~cm}$, WC AC $4 \mathrm{~cm}, \mathrm{AC}$ BC $13.5 \mathrm{~cm}$, LPA Class A $15 \mathrm{~cm}$. The results of drainage dimensions b $0.9 \mathrm{~m}$ and $1.1 \mathrm{~m}$ are planned along $2 \mathrm{~km}$ of KM Genteng $6+400$ (left) with a drainage gradient value of $60 \%$ and using cemented masonry material.
\end{abstract}

Keyword: Infrastructure, Flexible Pavement, Drainage, Banyuwangi

\section{PENDAHULUAN \\ Latar Belakang}

Jalan suatu prasarana yang mendukung dan berperan penting dalam sektor perhubungan, Dengan kondisi jalan yang baik lebih memudahkan mobilitas penduduk di suatu daerah dalam menjalankan kegiatan sosial dan perekonomian. Peningkatan prasarana transportasi darat dapat menunjang kelancaran dan pemerataan pembangunan di daerah maupun nasional. Namun, prasarana yang terbebani oleh volume lalu lintas yang tinggi dan berulang-ulang akan menyebabkan terjadinya penurunan kualitas jalan. Hal ini disebabkan oleh beberapa faktor antara lain beban kendaraan yang berlebihan (overloading), keadaan iklim dan lingkungan yang berubah -ubah, beban lalu lintas yang tinggi, perencanaan yang kurang tepat, pelaksanaan yang tidak sesuai dengan rencana yang ada, dan kurangnya pengawasan kondisi jalan.

Adapun jalan raya ini adalah jalan kelas II yang sering dilewati oleh kendaraan berat. Seperti diketahui jalan raya Benculuk ini merupakan jalan raya dari berbagai tujuan, Misalkan kendaraan berat (angkutan) dari jember ke banyuwangi. Misalkan seperti kendaraan pribadi, truk/truk gandengan atau semi/trailer yang mengangkut barang komoditi atau barang lainnya.

\section{Identifikasi Masalah}

Secara garis besar kerusakan dapat dibedakan menjadi dua bagian, yaitu kerusakan struktural, mencakup kegagalan perkerasan atau kerusakan dari satu atau lebih komponen 
perkerasan yang mengakibatkan perkerasan tidak dapat lagi menanggung beban lalu lintas; dan kerusakan fungsional yang mengakibatkan keamanan dan kenyamanan pengguna jalan menjadi terganggu sehingga biaya operasi kendaraan semakin meningkat. (Sulaksono,2001)

\section{Rumusan Masalah}

1. Berapa nilai kapasitas/kinerja pada ruas jalan raya Benculuk Kabupaten Banyuwangi.

2. Berapa tebal lapis perkerasan lentur dengan menggunakan metode Bina Marga 2013, dengan UR $=20$ tahun?

3. Berapa dimensi saluran drainase pada ruas jalan Benculuk kabupaten Banyuwangi?

\section{Batasan Masalah}

1. Ruang Lingkup penelitian ini pada ruas jalan raya Benculuk kabupaten banyuwangi.

2. Mengevaluasi kinerja jalan raya Benculuk Kabupaten Banyuwangi.

3. Mengevaluasi perencanaan tebal perkerasan lentur dengan metode Bina Marga 2013 pada jalan raya Benculuk Kabupaten Banyuwangi dengan usia rencana 20 tahun.

4. Mengevaluasi dimensi saluran drainase pada ruas jalan raya Benculuk kabupaten Banyuwangi.

\section{Tujuan}

1. Mengevaluasi kinerja/kapasitas jalan pada ruas jalan raya Benculuk Kabupaten Banyuwangi.

2. Menganalisa perencanaan tebal perkerasan dengan metode Bina Marga 2013.

3. Merencanakan dimensi saluran drainase pada ruas jalan raya Benculuk kabupaten Banyuwangi.

\section{TINJAUAN PUSTAKA Definisi Jalan}

Menurut UU.No.38 Tahun 2004 pasal 1 jalan adalah prasarana transportasi darat yang meliputi segala bagian jalan, termasuk bangunan pelengkap dan perlengkapan nya yang di peruntukkan bagi lalu lintas.

\section{Klasifikasi Jalan PP. Nomor 13/1970 Dirjen Bina Marga)}

Pada jalan dibagi dalam beberapa kelas dengan memperhatikan besarnya volume/jumah kendaraan serta sifat lalu lintas/kendaraan yang dilewati pengguna jalan.Adapun klasifikasi jalansebagai berikut :

\section{Kelas jalan menurut fungsinya}

1. Jalan utama adalah jalan raya yang melayani lalu lintas yang tinggi, cepat dan berat.

2. Jalan sekunder adalah jalan yang melayani antar kota yang lebih kecil dan daerah sekitarnya.

Kelas jalan menurut besarya volume dan sifat-sifat lalu lintas

\section{Kelas I}

Pada Kelas jalan I mencakup semua jalan utama dan dimaksud untuk melayani lalu lintas cepat dan berat. Dalam komposisi lalu lintas tidak terdapat kendaraan lambat dan kendaraan bermotor.

\section{Kelas II}

Kelas jalan II mencakup semua jalanjalan sekunder. Dalam komposisi lalu lintasnya terdapat lalu lintas lambat. Jalan kelas ini selanjutnya berdasarkan komposisi dan sifat lalu lintasnya.

\section{Kapasitas dan Derajat Kejenuhan Jalan}

Kapasitas jalan MKJI (1997) didefinisikan sebagai arus maksimum melalui suatu titik di jalan yang dapat dipertahankan per satuan jamnya pada kondisi tertentu. Untuk jalan dua-lajur dua-arah, kapasitas ditentukan untuk arus dua arah ( kombinasi dua arah ).

\section{Perhitungan Lalu-Lintas}

Perhitungan Lalulintas Masa Perencanaan

Rumus umum $=\operatorname{LHR}(\mathrm{n})=\operatorname{LHR}(0)(1+\mathrm{I})$ ..... (3)

Dengan perkembangan lalu-lintas $\quad(i)=\%$

Umum R encana tahun (n) = tahun

$\Sigma$ kendaraan tahun $\mathrm{LHR} n=\Sigma$ kendaraan tahun $2018 *(1+\mathrm{i}) \mathrm{n}$

\section{Tingkat Pelayanan Jalan}

Dalam penelitian evaluasi jalan terdapat beberapa parameter yang harus diteliti seperti 
alinyemen jalan, tebal perkerasan, volume kapasitas jalan dan tingkat pelayanan yang diberikan oleh jalan tersebut.

\section{Rencana Tebal Perkerasan Metode Bina Marga 2013}

Pada perhitungan perkerasan lentur dengan metode Bina Marga 2013, langkahlangkahnya sebagai berikut :

1. Penetapan Umur Rencana (UR) = tahun

2. Klasifikasi Kendaraan dan Nilai VDF standar

3. Menghitung ESA 20, dengan pertumbuhan lalu lintas (i)

4. Menghitung Faktor pengali pertumbumhan lalu lintas (R)

5. Nilai Multi Traffic Multiplier $(\mathrm{TM})=$ $1.8-2.0$

6. Menentukan Faktor Distribusi Lajur (DL)

7. Perhitungan CESA4, CESA5 dan ESA 20 tahun

8. Pemilihan Jenis Perkerasan

9. Solusi Desain 2 Pondasi Jalan minimum

10. Desain perkerasan lentur opsi biaya minimum

11. Tebal lapisan perkerasan ACWC, ACBC, CTB dan LPA (struktur perkerasan).

\section{Perencanaan Drainase \\ Daur Hidrologi}

Daur hidrologi adalah gerakan air ke udara yang kemudian jatuh ke permukaan tanah sebagai hujan atau bentuk presipitasi lain, dan akhirnya mengalir kelaut kembali.Daur hidrologi berguna untuk memberikan konsep pengantar mengenai bagaimana air bersirkulasi secara umum dan proses-proses yang terlibat dalam sirkulasi ini.

\section{Analisa Data Curah Hujan}

Data curah hujan yang digunakan dalam analisa terhadap alternatif penanganan banjir tersebut adalah data curah hujan yang maksimum. Hal ini bertujuan agar analisa dapat mendekati kondisi yang sebenarnya yang ada di lapangan.

\section{Menghitung Curah Hujan (CH) Rata-rata}

Data jumlah curah hujan $(\mathrm{CH})$ rata -rata untuk suatu daerah tangkapan air (catchment area) atau daerah aliran sungai (DAS) merupakan informasi yang sangat diperlukan oleh pakar bidang hidrologi.

\section{Perhitungan Curah Hujan Rencana}

Hujan rencana merupakan kemungkinan tinggi hujan yang terjadi dalam kala ulang tertentu sebagai hasil dari suatu rangkaian analisis hidrologi yang biasa disebut analisis frekuensi.

\section{Uji Keselarasan Distribusi}

Uji keselarasan dimaksudkan untuk menentukan persamaan distribusi peluang yang telah dipilih dapat mewakili distribusi statistik sampel data yang dianalisis. Ada dua jenis uji keselarasan, yaitu Chi Square dan Smirnov Kolmogorof.

\section{Perhitungan Intensitas (I)}

Curah hujan dalam jangka pendek dinyatakan dalam intensitas per jam yang disebut dengan intensitas curah hujan. Hujan dalam intensitas yang besar umumnya terjadi dalam waktu yang pendek. Hubungan intensitas hujan dengan waktu hujan banyak dirumuskan, yang pada umumnya tergantung pada parameter setempat.

\section{Metodologi Penelitian \\ Flow Chart}

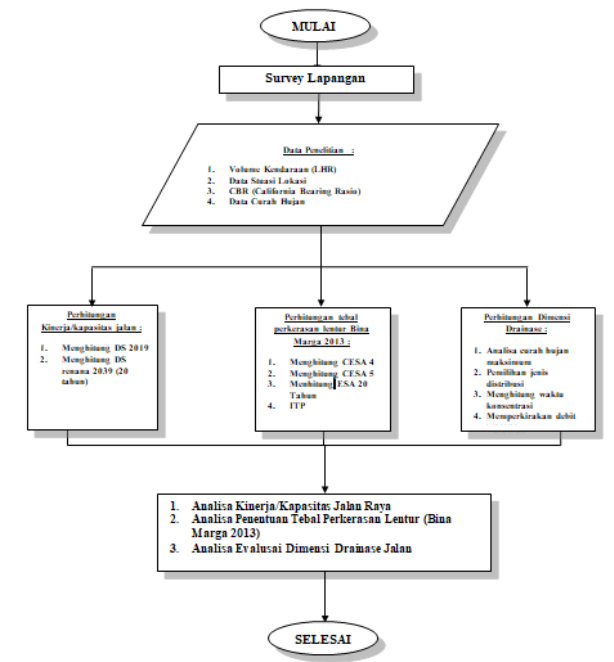

DATA DAN PEMBAHASAN

Data Lokasi Penentuan

Lokasi penelitian tugas akhir ini berada pada jalan raya benculuk kecamatan cluring kabupaten banyuwangi, Pada KM Genteng 06 + 400 (kiri) arah timur surabaya. Adapun penelitian hanya mengevaluasi Kinerja jalan, menghitung tebal perkerasan dengan menggunakan metode Bina Marga 2013 dan menganalisa drainase jalan. 


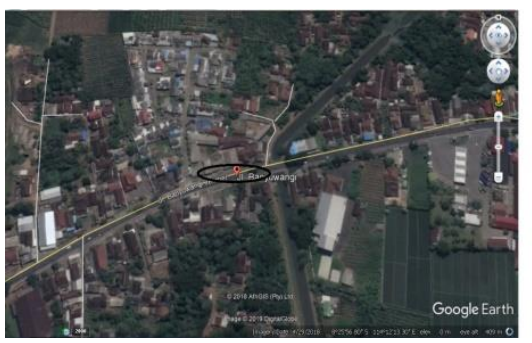

Gambar 1. Lokasi Penelitian Tugas Akhir

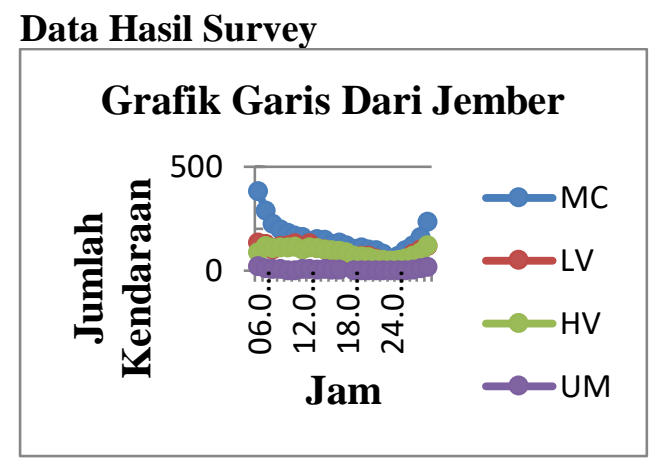

Gambar 2a. Grafik hasil survei

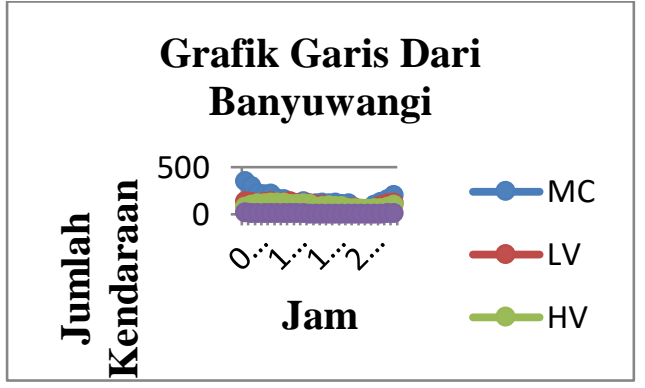

Gambar 2b. Grafik hasil survei

\section{Perhitungan Kinerja Jalan/Derajat Kejenuhan (DS)}

Tabel 1. Perhitungan Jam Puncak Total Kedua Arah Qsmp 2019

\begin{tabular}{|c|c|c|c|c|c|c|c|c|c|}
\hline \multirow[t]{2}{*}{ Alabh } & \multirow{2}{*}{$\begin{array}{l}\text { Pital } \\
\text { (WBiB) }\end{array}$} & \multirow{2}{*}{$\begin{array}{l}\text { Sepeda mortor, } \\
\text { mda3, Veppa }\end{array}$} & \multirow{2}{*}{ 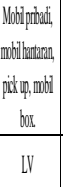 } & \multirow{2}{*}{ 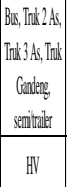 } & \multirow{2}{*}{$\begin{array}{c}\text { ENP } \\
\text { WKI } 199 ?\end{array}$} & \multicolumn{3}{|c|}{ QSWP } & \multirow[t]{2}{*}{$\begin{array}{l}\text { Todal } \\
\text { SMPP }\end{array}$} \\
\hline & & & & & & $\mathbb{M C}$ & LV & $\mathbb{H V}$ & \\
\hline 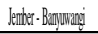 & $06,0.007 .7 .00$ & 381 & 136 & 88 & 0,6 & 95,25 & 136 & 105,6 & 36,85 \\
\hline Barywangy- Eemper & $060.00-17.00$ & 300 & 133 & 73 & 1 & 87,5 & 133 & 87,6 & 308,1 \\
\hline \multicolumn{2}{|l|}{ Total } & 731 & 269) & 161 & 1.2 & 18275 & 269 & 193,2 & $(645,0)$ \\
\hline
\end{tabular}

Untuk C smp = 2586,22 smp/jam dan Qsmp = 645,0 smp/jam, sehingga didapat DS, sebagai berikut:

$$
\begin{aligned}
\mathrm{DS} & =\mathrm{Q} / \mathrm{C}=645,0 / 2586,22 \\
& =0,249398736(\mathrm{~B})
\end{aligned}
$$

Dimana hasil DS $=\mathbf{0 , 2 4 9 3 9 8 7 3 6}(\mathbf{B})$ adalah Dalam zone arus stabil, Pengemudi memiliki kebebasan yang cukup untuk memilih kecepatannya.
Tabel 2. Tabel Perhitungan Jam Puncak Qsmp 2039

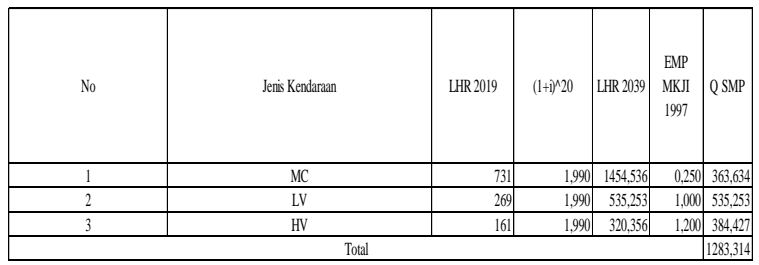

Untuk C smp $=2586,22$ smp/jam dan Qsmp = 1283,314 smp/jam, sehingga didapat DS, sebagai berikut:

$$
\mathrm{DS}=\mathrm{Q} / \mathrm{C}=1283,314 / 2586,22=
$$
0,496212233 (C)

Dimana hasil DS $=\mathbf{0 , 5 4 8 1 1 1 4 6 7}(\mathbf{C})$ adalah dalam zone harus stabil pengemudi dibatasi dalam memilih kecepatannya.

Tabel 3. Kriteria \& Tingkat Pelayanan Jalan

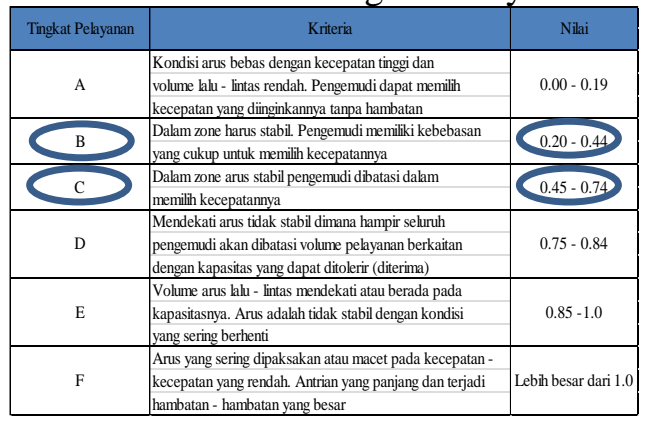

Perhitungan Perkerasan Lentur Bina Marga 2013

1. Umur Rencana $=20$ tahun (direncanakan), sesuai Manual Perkerasan jalan No.02/M/BM/2013 halaman 9, yaitu lapisan lentur berbutir dan CTB

Dalam perencanaan tebal lapisan perkerasan perlu adanya umur rencana jalan tersebut masih dapat dipakai.

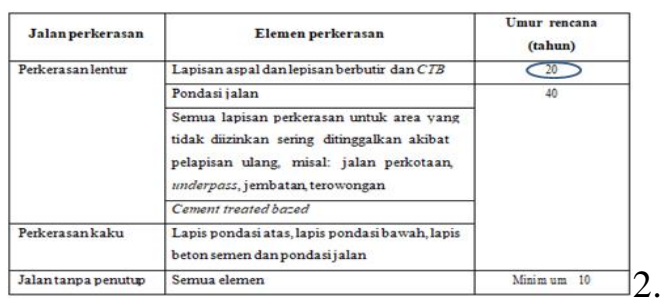

Klasifikasi Kendaraan dan Nilai VDF4 standar :

\begin{tabular}{|l|r|}
\hline \multicolumn{1}{|c|}{ Jenis Kendaraan } & VDF 4 \\
\hline $\begin{array}{l}\text { Kendaraan ringan, mobil } \\
\text { pribadi, pick up, mobil box, } \\
\text { mobil hantaran. }\end{array}$ & 0,3 \\
\hline Bus & 1,0 \\
\hline Truk 2 as & 0,8 \\
\hline Truk 3 as & 7,6 \\
\hline Truk Gandengan, semi/trailer & 13,6 \\
\hline
\end{tabular}


3. Pertumbuhan lalu lintas (Tabel Pertumbuhan lalu lintas tahun 2011-2020 ) sebesar 3,5\% (untuk jalan Kolektor Rural).

\begin{tabular}{|l|c|c|}
\hline & $2011-2020$ & $>2021-2030$ \\
\hline Arteri dan Perkotaan (\%) & 5 & 4 \\
\hline Kolektor Rural (\%) & 3,5 & 2,5 \\
\hline Jalan Desa (\%) & 1 & 1 \\
\hline
\end{tabular}

4. Perhitungan $\mathrm{R}$

$$
\begin{aligned}
& \mathrm{i}=(3,5 \%) 3,5 / 100=0,035 \\
& \mathrm{UR}=20 \text { Tahun } \\
& \mathrm{R}=1+(0,01 * 0,035)^{\wedge} 20-1 \\
& \mathrm{R}=1,007023 \\
& \mathrm{R}=0,007023 \\
& \mathrm{R}=0,007023 /(0,01 * 0,035) \\
& \mathrm{R}=20,06664
\end{aligned}
$$

5. Menentukan nilai Traffic Miltiplier (TM), Nilai Traffic Multiplier (TM) kelelahan lapisan aspal untuk kondisi pembebanan yang berlebih di indonesia berkisar $=1,8-2,0$

\begin{tabular}{|c|c|c|c|c|c|c|}
\hline № & Jenis Kendaraan & $\begin{array}{c}\text { LHRIAM } \\
2019 \\
\end{array}$ & VDF4 & ESA4 & CESA4 & ESAS \\
\hline 1 & $\begin{array}{l}\text { Kendaraan ingan, mobil pribadi, } \\
\text { mobil box, mobil hantaran }\end{array}$ & 186,625 & 0,3 & 55,9875 & 328056,452 & 623307,258 \\
\hline 2 & Bus & 43,750 & 1,0 & 43,75 & 256351,324 & 487067,516 \\
\hline 3 & Trik 2 as & 79,458 & 0,8 & 63,5667 & 372466,267 & 707685,907 \\
\hline 4 & Truk 3 as & 38,708 & 7,6 & 294,183 & 1723755,133 & 3275134,752 \\
\hline 5 & Truk Gandengan, seni traler & 13,375 & 13,6 & 181,9 & 1065835,563 & 2025087,569 \\
\hline \multicolumn{4}{|c|}{ Jumlah } & 639,388 & 3746464,738 & 7118283,002 \\
\hline
\end{tabular}
disini diambil rata-rata yaitu 1,9 .

6. Menentukan DL $=80 \%$ dengan 2 lajur setiap arah

\begin{tabular}{|c|c|}
\hline Jumlah Lajur & $\begin{array}{c}\text { Kendar aan Niaga Pada Lajur Desain } \\
\text { (\% Terhadap Populasi Kendaraan Niaga) }\end{array}$ \\
\hline Setiap Arah & 100 \\
\hline 1 & 80 \\
\hline 3 & 60 \\
\hline 4 & 50 \\
\hline
\end{tabular}

7. Perhitungan CESA4, CESA5 dan ESA 20 tahun

8. Dari perhitungan CESA4, CESA5 dan ESA 20 tahun dapat diambil pemilihan jenis perkerasaan pada ESA 20 tahun = 7.118.283,002

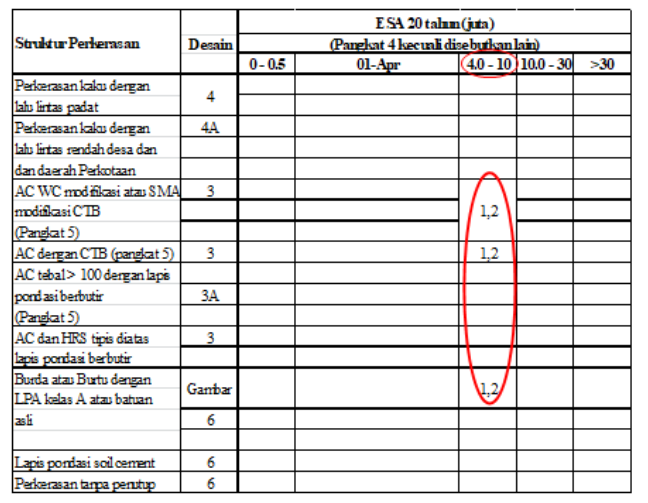

9. Solusi desain pondasi jalan minimum

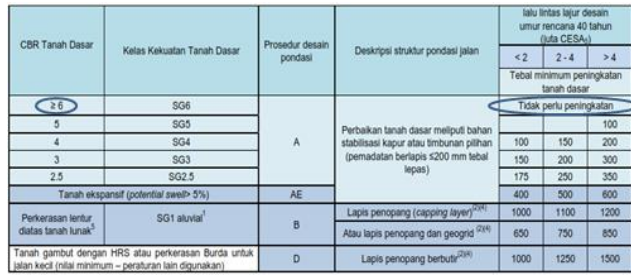

10. Desain perkerasan lentur opsi biaya minimum

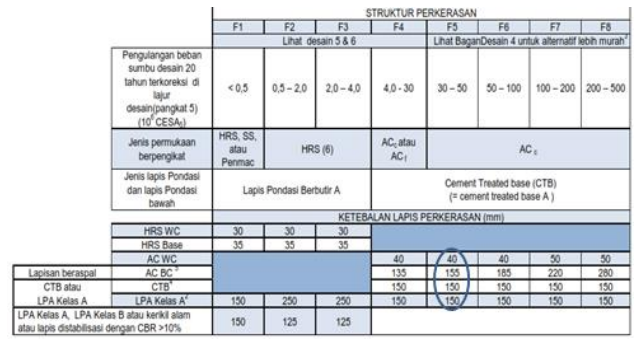

11. Hasil Perhitungan Tebal Lapis Perkerasan AC WC, AC BC, LPA A atau LPA Kelas A (struktur perkerasan)

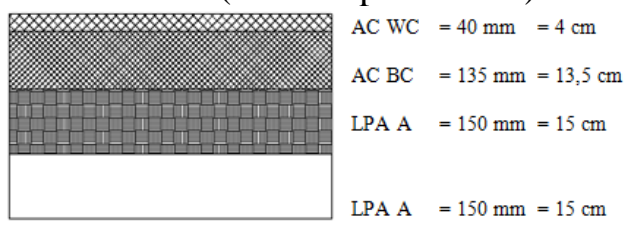

Gambar 3. Hasil Perhitungan Tebal Lapis Perkerasan

12. Kondisi Eksisting Perkerasan Pada Ruas Jalan Banyuwangi - Jember Tahun 2019 sebesar $42-43 \mathrm{~cm}$, dapat digambarkan sebagai berikut :

$\begin{array}{lll}\text { AC WC } & =40 \mathrm{~mm}=4 \mathrm{~cm} \\ \text { AC BC } & =135 \mathrm{~mm}=13,5 \mathrm{~cm} \\ \text { LPA A } & =125 \mathrm{~mm}=12,5 \mathrm{~cm} \\ \text { LPA A } & =125 \mathrm{~mm} & =12,5 \mathrm{~cm}\end{array}$

Gambar 4. Kondisi Eksisting Perkerasan

\section{Dimensi Saluran}

Dalam perencanaan jaringan dan saluran drainase, terlebih dahulu harus mengetahui debit maksimum rancangan dengan kala ulang tahun tertentu dan peneliti merencanakan debit maksimum selama 10 tahun, dari debit tersebut maka dapat direncanakan dimensi saluran. Untuk dimensi saluran menggunakan saluran yang berbentuk trapesium antara lain : 1. Lebar dasar saluran (b) adalah lebar pada dasar saluran $=0,9 \mathrm{~m}$

2. Kedalaman aliran (h) adalah jarak vertikal titik terendah pada suatu penampang saluran sampai ke permukaan bebas dan untuk nilai $\mathrm{h}$ penampang ekonomisnya $=1,1 \mathrm{~m}$. Mencari nilai $\mathrm{b}$ dan $\mathrm{h}$ dilakukan dengan cara coba-coba.

3. Lebar puncak (T) adalah lebar penampang saluran pada permukaan bebas, 
karena saluran berbentuk trapesium jadi nilai $\mathrm{T}=\mathrm{b}=0,9 \mathrm{~m}$.

4. Luas basah (A) adalah luas penampang melintang aliran yang tegak lurus dengan arah aliran.

$$
\begin{aligned}
& \text { A } \quad=\mathrm{b} \times \mathrm{h} \\
& =0,9 \times 1,1 \\
& =0,99 \mathrm{~m} 2
\end{aligned}
$$

5. Keliling basah (P) adalah panjang garis perpotongan dari permukaan basah saluran dengan bidang penampang melintang yang tegak lurus arah aliran.

$$
\begin{aligned}
\mathrm{P} & =\mathrm{B}+2 \mathrm{H} \times(\mathrm{m} 2+1)^{\wedge} 1 / 2 \\
& =0,9+2 \times 1,1 \times\left(1^{\wedge} 2+1\right)^{\wedge}(0,5) \\
& =4,011269837 \mathrm{~m}
\end{aligned}
$$

6. Jari - jari hidrolik (R) adalah rasio luas basah dengan keliling basah.

$$
\begin{aligned}
\mathrm{R} & =\mathrm{A} / \mathrm{P} \\
& =0,99 / 4,011269837 \\
& =0,246804638 \mathrm{~m}
\end{aligned}
$$

7. Menurut data perencanaan dinding saluran menggunakan pasangan batu disemen, maka nilai koefisien kekasaran manning sebesar $\mathrm{n}=35$

8. Dalam penelitian ini kecepatan aliran menggunakan metode strickler dengan persamaan sebagai berikut :

$$
\begin{array}{ll}
\mathrm{K} & =\text { Koefisien kekasaran } \\
\mathrm{R} & =\text { Radius hidrolik }=0,246804638 \mathrm{~m} \\
\mathrm{I} & =\text { Kemiringan saluran }=0,0026 \\
\mathrm{~V} & =\text { Kecepatan aliran dalam saluran } \\
(\mathrm{m} / \mathrm{dtk}) & \\
\mathrm{V} & =\mathrm{K} \times \mathrm{R} 2 / 3 \times \mathrm{I} 1 / 2 \\
& =1,19577257 \mathrm{~m} / \mathrm{dtk}
\end{array}
$$

9. Untuk menentukan debit saluran drainase digunakan rumus umum yaitu :

A $\quad=$ Penampang dasar saluran $=0,99 \mathrm{~m} 2$

$\mathrm{V}=$ Kecepatan aliran dalam saluran $=$ $1,19577257 \mathrm{~m} / \mathrm{dtk}$

$$
\begin{aligned}
\mathrm{Q} & =\mathrm{V} \times \mathrm{A} \\
& =0,99 \times 1,19577257 \\
& =1,1838 \mathrm{~m} 3 / \mathrm{dtk}
\end{aligned}
$$

Gambar Penampang Saluran

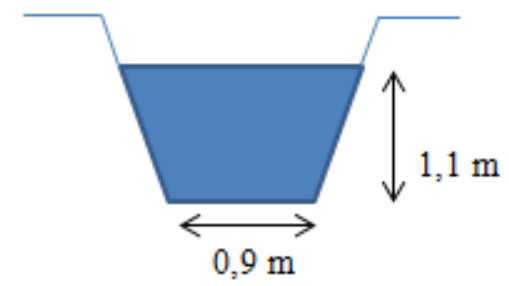

Gambar 4. Penampang Saluran

\section{KESIMPULAN DAN SARAN Kesimpulan}

1. Kinerja pada ruas jalan raya Benculuk kelas II (Kabupaten) KM Genteng 6+400 (Kiri) kecamatan Cluring kabupaten Banyuwangi berdasarkan hasil survey didapat volume lalu - lintas didapat pada tahun 2019 $\mathrm{Q}=645,0 \mathrm{smp} / \mathrm{jam}$ didapatkan $\mathrm{DS}=0,24$ dengan tingkat pelayanan (B), yakni Dalam zone arus stabil, Pengemudi memiliki kebebasan yang cukup untuk memilih kecepatannya, dengan asumsi $\mathrm{i}=3,5 \%$ maka tahun 2039 didapat $\mathrm{Q}=1283,314 \mathrm{smp} / \mathrm{jam}$ dengan DS $=0,49$ (C) adalah dalam zone harus stabil pengemudi dibatasi dalam memilih kecepatannya.

2. Untuk perhitungan tebal perkerasan lentur metode Bina Marga 2013 sebagai berikut :

$\mathrm{AC} \mathrm{WC}=40 \mathrm{~mm} \quad=4 \mathrm{~cm}$

$\mathrm{AC} \mathrm{BC}=135 \mathrm{~mm} \quad=13,5 \mathrm{~cm}$

LPA Kelas $A=150 \mathrm{~mm}=15 \mathrm{~cm}$

LPA Kelas $A=150 \mathrm{~mm}=15 \mathrm{~cm}$

Jumlah $\quad=47,5 \mathrm{~cm}$

Dari hasil perhitungan (analisis) tebal lapis perkerasan dengan metrode Bina Marga 2013 $=47,5 \mathrm{~cm}$ dan eksisting dilapangan tebal lapis perkerasan $=42-43 \mathrm{~cm}$, maka selisih tebal lapis perkerasan $=4,5-5,5 \mathrm{~cm}$ (lebih tebal lapis perkerasan).

3. Hasil evaluasi yang dibutuhkan saluran drainase $b=0,9 \mathrm{~m}$ dan $\mathrm{h}=1,1 \mathrm{~m}$ yang direncanakan sepanjang $2 \mathrm{~km}$ pada $\mathrm{KM}$ Genteng $6+400$ (Kiri) dengan nilai gradien drainase $60 \%$ dan menggunakan material pasangan batu disemen.

\section{Saran}

Saran dari penulis sebagai berikut :

1. Diperlukan adanya perhitungan kembali pada tebal perkerasan baik dengan metode Bina Marga 2013, Hal ini disebabkan karena kendaraan yang melewati jalur tersebut terdapat kendaraan berat (Banyuwangi - Jember ataupun Jawa Bali).

2. Perlunya pengadaan peraturan untuk angkutan berat pada ruas jalan raya benculuk tersebut.

3.Pemerintah sekitar perlu mengadakan pengawasan untuk menjaga kebersihan lingkungan drainase dengan baik secara berkesinambungan. 


\section{REFRENSI}

1997, Manual Kapasitas Jalan Indonesia (MKJI), Direktorat Jendral Bina Marga Departemen Pekerjaan Umum, Jakarta

1983, Pedoman PenentuanTebal Perkerasan Lentur Jalan Raya No : 01/PD/B/1983, Direktorat Jemdral Bina Marga Departemen Pekerjaan Umum, Jakarta

Noor Salim Ir, M.Eng, Buku Diktat Perencanaan Jalan Raya I, Unmuh Jember,2013.

2018, Pertumbuhan Penduduk Banyuwangi 2018. Badan Pusat Statistik Kabupaten Banyuwangi, Banyuwangi.
Willy Alexander 2012, Tugas Akhir, Evaluasi Kinerja Dan Tebal Perkerasan Jalan Raya Tapen Kabupaten Bondowoso (Perbandingan Metode Bina Marga Tahun 1987 dan Tahun 2013).

Muhammad Fikri Kurniawan 2012, Tugas Akhir, Evaluasi Kinerja Jalan Kartini Kencong Jember Berdasarkan Kondisi Drainase Dan Perkerasan Lentur.

Saiful Rizal, Nanang, ST,MT, Aplikasi Perencanaan Irigasi dan Bangunan Air, 2014, Jember : LPPM Universitas Muhammadiyah Jember.

Suripin 2004 Sistem Drainase Perkotaan yang Berkelanjatuan. Andi Offset : Yogyakarta. 